Cochrane Database of Systematic Reviews

\title{
Antibiotic use for irreversible pulpitis (Review)
}

Agnihotry A, Thompson W, Fedorowicz Z, van Zuuren EJ, Sprakel J

Agnihotry A, Thompson W, Fedorowicz Z, van Zuuren EJ, Sprakel J.

Antibiotic use for irreversible pulpitis.

Cochrane Database of Systematic Reviews 2019, Issue 5. Art. No.: CD004969.

DOI: 10.1002/14651858.CD004969.pub5.

www.cochranelibrary.com 
TABLE OF CONTENTS

ABSTRACT

PLAIN LANGUAGE SUMMARY

SUMMARY OF FINDINGS

BACKGROUND

OBJECTIVES

METHODS

RESULTS

Figure 1.

Figure 2.

DISCUSSION

AUTHORS' CONCLUSIONS

ACKNOWLEDGEMENTS

REFERENCES

CHARACTERISTICS OF STUDIES

ADDITIONAL TABLES

APPENDICES

WHAT'S NEW

HISTORY

CONTRIBUTIONS OF AUTHORS

DECLARATIONS OF INTEREST

SOURCES OF SUPPORT

NOTES

INDEX TERMS 
[Intervention Review]

\section{Antibiotic use for irreversible pulpitis}

Anirudha Agnihotry ${ }^{1}$, Wendy Thompson ${ }^{2}$, Zbys Fedorowicz ${ }^{3}$, Esther J van Zuuren ${ }^{4}$, Julie Sprakel ${ }^{5}$

1Family Healthcare Network, Porterville, California, USA. ${ }^{2}$ School of Dentistry, University of Leeds, Leeds, UK. ${ }^{3}$ Veritas Health Sciences Consultancy Ltd, London, UK. ${ }^{4}$ Department of Dermatology, Leiden University Medical Center, Leiden, Netherlands. ${ }^{5}$ Department of Gynecology and Obstetrics, Ribeiro Preto Medical School, University of Sao Paulo, Sao Paulo, Brazil

Contact: Anirudha Agnihotry, Family Healthcare Network, Porterville, California, CA 93257, USA. anirudha.agnihotry@gmail.com.

Editorial group: Cochrane Oral Health Group.

Publication status and date: Stable (no update expected for reasons given in 'What's new'), published in Issue 7, 2019.

Citation: Agnihotry A, Thompson W, Fedorowicz Z, van Zuuren EJ, Sprakel J. Antibiotic use for irreversible pulpitis. Cochrane Database of Systematic Reviews 2019, Issue 5. Art. No.: CD004969. DOI: 10.1002/14651858.CD004969.pub5.

Copyright ( 2019 The Cochrane Collaboration. Published by John Wiley \& Sons, Ltd.

\section{A B S T R A C T}

\section{Background}

Irreversible pulpitis, which is characterised by acute and intense pain, is one of the most frequent reasons that patients attend for emergency dental care. Apart from removal of the tooth, the customary way of relieving the pain of irreversible pulpitis is by drilling into the tooth, removing the inflamed pulp (nerve) and cleaning the root canal. However, a significant number of dentists continue to prescribe antibiotics to stop the pain of irreversible pulpitis.This review updates the previous version published in 2016.

\section{Objectives}

To assess the effects of systemic antibiotics for irreversible pulpitis.

\section{Search methods}

We searched Cochrane Oral Health's Trials Register (to 18 February 2019); the Cochrane Central Register of Controlled Trials (CENTRAL; 2019, Issue 1) in the Cochrane Library (searched 18 February 2019); MEDLINE Ovid (1946 to 18 February 2019); Embase Ovid (1980 to 18 February 2019); US National Institutes of Health Ongoing Trials Register ClinicalTrials.gov (searched 18 February 2019); and the World Health Organization International Clinical Trials Registry Platform (searched 18 February 2019). There were no language restrictions in the searches of the electronic databases.

\section{Selection criteria}

Randomised controlled trials which compared pain relief with systemic antibiotics and analgesics, against placebo and analgesics in the acute preoperative phase of irreversible pulpitis.

\section{Data collection and analysis}

Three review authors screened studies and extracted data independently. We assessed the certainty of the evidence of included studies using GRADE. Pooling of data was not possible and a descriptive summary is presented.

\section{Main results}

No additional trials could be included in this update. One trial at low risk of bias evaluating oral penicillin in combination with analgesics versus placebo with analgesics, involving 40 participants was included in a former update of the review. The certainty of the evidence was rated low for the different outcomes. Our primary outcome was patient-reported pain (intensity/duration) and pain relief. There was a close parallel distribution of the pain ratings in both the intervention (median 6.0, interquartile range (IQR) 10.5), and for placebo (median 6.0, IQR 9.5) over the seven-day study period. There was insufficient evidence to claim or refute a benefit for penicillin for pain intensity. There was no significant difference in the mean total number of ibuprofen tablets over the study period: 9.20 (standard deviation (SD) 6.02) in the penicillin group versus 9.60 (SD 6.34) in the placebo group; mean difference $-0.40(95 \%$ confidence interval $(\mathrm{Cl})-4.23$ to $3.43 ; \mathrm{P}=$ 
0.84). This applied equally for the mean total number of Tylenol tablets: 6.90 (SD 6.87) used in the penicillin group versus 4.45 (SD 4.82 ) in the placebo group; mean difference $2.45(95 \% \mathrm{Cl}-1.23$ to $6.13 ; \mathrm{P}=0.19)$. Our secondary outcome on reporting of adverse events was not addressed in this study.

\section{Authors' conclusions}

This Cochrane Review which was based on one low-powered small sample trial assessed as at low risk of bias, illustrates that there is insufficient evidence to determine whether antibiotics reduce pain or not compared to not having antibiotics. The results of this review confirm the necessity for further larger sample and methodologically sound trials that can provide additional evidence as to whether antibiotics, prescribed in the preoperative phase, can affect treatment outcomes for irreversible pulpitis.

\section{PLAIN LANGUAGE SUMMARY}

\section{Antibiotic use for severe toothache (irreversible pulpitis)}

\section{Review question}

Are oral antibiotics effective and safe for treating pain in irreversible pulpitis (inflammation of the nerve inside the tooth/nerve damage)?

\section{Background}

Irreversible pulpitis occurs where the dental pulp (tissue inside the tooth which contains the nerve) has been damaged beyond repair. It is characterised by intense pain (toothache), sufficient to wake someone up at night and is considered to be one of the most frequent reasons that patients attend for emergency dental care. Any tooth may be affected, it is not restricted to particular age groups, and it usually occurs as a direct result of dental decay, a cracked tooth, or trauma.

The 'standard of care' for irreversible pulpitis - immediate removal of the pulp from the affected tooth - is now widely accepted and yet in certain parts of the world antibiotics continue to be prescribed.

\section{Study characteristics}

The evidence on which this review is based was current as of 18 February 2019. One study involving 40 people with irreversible pulpitis (nerve damage) was included. There were two groups of 20 people, one group was treated with penicillin $500 \mathrm{mg}$, the other with placebo (no active ingredient) every six hours over a seven-day period. In addition, all of the participants received painkillers (ibuprofen and paracetamol (acetaminophen) combined with codeine).

\section{Key results}

Antibiotics do not appear to significantly reduce toothache caused by irreversible pulpitis. Furthermore, there was no difference in the total number of ibuprofen or Tylenol tablets used over the study period between both groups. The administration of penicillin does not significantly reduce the pain perception, the percussion (tapping on the tooth) perception, or the quantity of pain medication required by people with irreversible pulpitis. There was no reporting on adverse events or reactions.

\section{Certainty of the evidence}

This was a study with a small number of participants and the certainty of the evidence for the different outcomes was rated as low. There is currently insufficient evidence to be able to decide if antibiotics help for this condition. This review highlights the need for more and better quality studies on the use of antibiotics for irreversible pulpitis. 


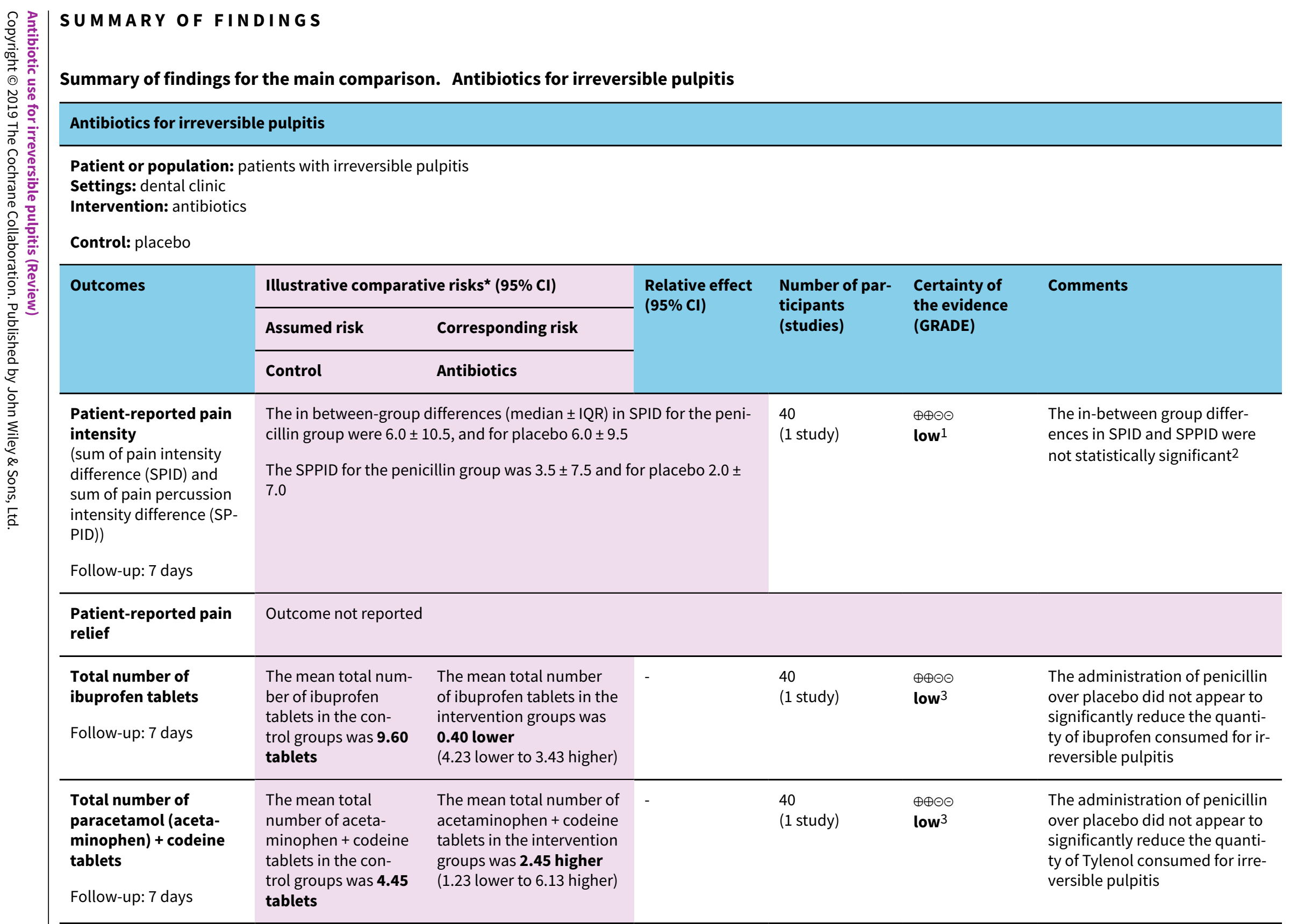

Settings: dental clinic

Control: placebo 
*The basis for the assumed risk (e.g. the median control group risk across studies) is provided in footnotes. The corresponding risk (and its $95 \% \mathrm{Cl}$ ) is based on the assumed risk in the comparison group and the relative effect of the intervention (and its $95 \% \mathrm{Cl}$ )

Cl: confidence interval; IQR: interquartile range

\section{GRADE Working Group grades of evidence}

High certainty: we are very confident that the true effect lies close to that of the estimate of the effect

Moderate certainty: we are moderately confident in the effect estimate; the true effect is likely to be close to the estimate of the effect, but there is a possibility that it is substantially different

Low certainty: our confidence in the effect estimate is limited; the true effect may be substantially different from the estimate of the effect

Very low certainty: we have very little confidence in the effect estimate; the true effect is likely to be substantially different from the estimate of effect

1Downgraded 2 levels for very serious imprecision (very small sample size).

2The between-group differences in SPID (median; IQR) for the penicillin group were $6.0 \pm 10.5$ and for placebo $6.0 \pm 9.5, P=0.776$. The SPPID (median; IQR) for the penicillin group were $3.5 \pm 7.5$ and placebo $2.0 \pm 7.0, P=0.290$.

${ }^{3}$ Downgraded 2 levels for very serious imprecision (very small sample size and $95 \% \mathrm{Cl}$ includes no effect and both the upper and lower confidence limit crosses the minimal important difference). 


\section{B A C K G R O U N D}

Dental emergencies are extremely common. A survey conducted in the UK recorded that $16 \%$ of the population had experienced toothache in the preceding year (Steele 2011). Non-traumatic dental condition visits account for $1.4 \%$ of all emergency department visits in the USA and have shown an annual rise of $4 \%$ (from 1\% in 1997 to $1.7 \%$ in 2007) (Onkunseri 2012). Dental caries (tooth decay) is the result of bacterial attack on a tooth and is the precursor to irreversible pulpitis, which is considered to be an immune system mediated event affecting the dental pulp (nerve) rather than an infective condition of the pulp (Bergenholtz 1990). Acute and intense pain are the most typical presenting symptoms of irreversible pulpitis. It occurs more commonly in vital teeth beneath deep caries before the bacteria have even reached the pulp (Hahn 1991). Thus the involved tooth will usually have an extensive restoration (filling) or caries or both under which death of the pulp may occur quite quickly or which may take years to occur even if the dental caries is removed (Tronstad 1991).

\section{Description of the condition}

Irreversible pulpitis is caused by a vital inflamed pulp which is incapable of healing (Hargreaves 2015). The symptoms are a continuum and can vary but usually include a history of spontaneous pain which may also involve an exaggerated response to hot or cold that lingers after the stimulus is removed (Soames 1998). Any tooth may be affected by irreversible pulpitis, it is not restricted to particular age groups and occurs as a direct result of dental caries, a cracked tooth, or trauma. The involved tooth is usually not sensitive to percussion, and palpation tests do not produce an untoward reaction. The characteristics of irreversible pulpitis are a vital pulp which responds to cold and electric pulp testing. A number of variations of irreversible pulpitis have been recognised (Hargreaves 2015). These include acute, subacute, chronic, partial or total, infected or sterile, however it is not possible to clearly differentiate these except by histopathological methods.

\section{Description of the intervention}

Although not indicated by current guidance, it is recognised that a range of oral antibiotics with differing dosing regimens may in fact be prescribed (SDCEP 2016). Antibiotics commonly prescribed by dentists include: ß-lactams (amoxicillin, penicillin V, co-amoxiclav), macrolides, tetracyclines, clindamycin, and metronidazole (DarOdeh 2010).

\section{How the intervention might work}

Pulpitis is an inflammatory reaction of the pulp and often occurs without any evidence of bacteria in the pulp chamber. Antibiotics have bactericidal or bacteriostatic properties or both, and are used widely to control or eliminate bacteria, but the mode of action and extent to which antibiotics have an anti-inflammatory or analgesic effect in irreversible pulpitis remains less clear.

\section{Why it is important to do this review}

There is limited and what appears to be largely anecdotal evidence to support the routine prescribing of antibiotics for irreversible pulpitis. It is likely that the practice of prescribing of antibiotics may have arisen due to a misconception of the natural pathological process of pulpitis (pain resolves when the pulp devitalises irrespective of antibiotic use), or the perception that antibiotics should be prescribed prophylactically in anticipation of pain arising prior to endodontic treatment. Either of these approaches may have promoted the inappropriate prescribing of antibiotics for endodontic emergencies. A study conducted in the USA of members of the American Association of Endodontists (AAE) surveyed their prescribing practices and reported that $16.7 \%$ of the specialist endodontists prescribed antibiotics for cases of irreversible pulpitis (Yingling 2002). A similar study in Spain with members of the Spanish Endodontic Society found a figure of 40\% (RodriguezNúñez 2009). General dental practitioners are often the first point of contact for patients with irreversible pulpitis and although one study conducted in Belgium reported that a smaller proportion $(4.3 \%)$ of general dentists continue to prescribe antibiotics for irreversible pulpitis (Mainjot 2009), another study conducted in Spain indicated that a substantial number (86\%) of respondents continue to do so (Segura-Egea 2010). A more recent study in UK general dental practices found $19.4 \%$ of dental antibiotics were prescribed for irreversible pulpitis (Cope 2016), whilst a UK dental hospital's acute dental care department audit found $70 \%$ of antibiotics prescribed for pulpitis in the first cycle of a clinical audit and $20 \%$ in the second cycle (Chopra 2014). To further investigate the prescribing behaviours of the general dentists and endodontists, we conducted a survey with the same question as of this review and found that one in every four dentists would prescribe antibiotics, when not needed (Agnihotry 2014a). In a more recent study (Cope 2016), it was found out that more than half of the sample size of general dentists (65.6\%) prescribed antibiotics when there was no evidence of spreading infection.

Unnecessary use of antibiotics is driving the global increase in drug-resistant infections and action is required across government and society including health care and agriculture (O'Neill 2016). Antibiotics are the corner stone of modern medicine; without effective antibiotics the success of major surgery and cancer chemotherapy will be compromised (WHO 2018). Life-threatening infections caused by Klebsiella pneumoniae which are now resistant to the last resort treatment (carbapenems) have spread worldwide; treatment failure to the last resort of medicine for gonorrhoea (third generation cephalosporin antibiotics) has been confirmed in at least 10 countries (Australia, Austria, Canada, France, Japan, Norway, Slovenia, South Africa, Sweden, and the UK (WHO 2018). By 2050, it is expected that deaths from antimicrobial resistant infections will be higher than from cancer (O'Neill 2016). Although the inappropriate prescribing of antibiotics for endodontic emergencies has received much attention (Agnihotry 2014; Fouad 1996; Palmer 2003; Segura-Egea 2018), it remains unclear to what extent this may have contributed to the development of resistant strains of bacteria and the growing problem of antibiotic resistance (CDC 2008; SMAC 1997).

Other adverse events associated with dental antibiotic use have been reported, including its contribution to the incidence of Clostridium difficile in the community (Bye 2017). Antibioticrelated colitis caused by $C$ diff is associated with significant morbidity and can be life threatening, especially for elderly and medically compromised patients (Beacher 2015). Increasing rates of anaphylaxis to antibiotics have also been reported (Turner 2015).

Irreversible pulpitis, at least in the early phase, is not normally accompanied by the clinical signs of bacterial infection, i.e. swelling and tenderness of adjacent mucosa, which more generally manifests itself after the pulp has become necrotic and the infected 
pulpal tissues pass into the periapical region (Cope 2018). Although some dentists continue to prescribe antibiotics, there appears to be very limited evidence that penicillin reduces pain, percussion sensitivity, or the amount of analgesics required in untreated teeth diagnosed with irreversible pulpitis (Nagle 2000).

Immediate pulpectomy is now widely accepted as the 'standard of care' for irreversible pulpitis (Segura-Egea 2018; Walton 2009) and yet in certain parts of the world antibiotics continue to be prescribed. We consider that a systematic review is still necessary to provide further evidence of the effects of antibiotics and ultimately more clarity and guidance in the management of this clinical condition.This review updates the previous version published in 2016 (Agnihotry 2016).

\section{O B J E C T IVES}

To assess the effects of systemic antibiotics for irreversible pulpitis.

\section{METHOD S}

\section{Criteria for considering studies for this review}

\section{Types of studies}

Randomised controlled trials (RCTs) were considered in this review.

\section{Types of participants}

We included adult patients who were over the age of 18 and presented with a single tooth with a clinical diagnosis of irreversible pulpitis.

\section{Types of interventions}

\section{Active interventions}

Administration of any systemic antibiotic at any dosage and any analgesic at any dosage prescribed in the acute preoperative phase of irreversible pulpitis.

\section{Control}

Administration of placebo and any analgesic, at any dosage, prescribed in the acute preoperative phase of irreversible pulpitis.

\section{Types of outcome measures}

\section{Primary outcomes}

- Patient-reported pain (intensity/duration) and pain relief measured on a categorical scale in the preoperative phase of irreversible pulpitis.

\section{Secondary outcomes}

- Type, dose, and frequency of medication required for pain relief.

- Any adverse effects related to any clinically diagnosed hypersensitivity or other reactions to either the antibiotics or analgesics.

\section{Search methods for identification of studies}

\section{Electronic searches}

Cochrane Oral Health's Information Specialist conducted systematic searches in the following databases for randomised controlled trials and controlled clinical trials. There were no language, publication year or publication status restrictions.
For this update we searched the following databases:

- Cochrane Oral Health's Trials Register (searched 18 February 2019) (Appendix 1);

- the Cochrane Central Register of Controlled Trials (CENTRAL; 2019, Issue 1) in the Cochrane Library (searched 18 February 2019) (Appendix 2);

- MEDLINE Ovid (1946 to 18 February 2019) (Appendix 3);

- Embase Ovid (1980 to 18 February 2019) (Appendix 4).

Subject strategies were modelled on the search strategy designed for MEDLINE Ovid.

\section{Searching other resources}

The following trial registries were searched for ongoing studies (see Appendix 5 for the search strategy):

- US National Institutes of Health Ongoing Trials Register ClinicalTrials.gov (searched 18 February 2019);

- World Health Organization International Clinical Trials Registry Platform (apps.who.int/trialsearch; searched 18 February 2019).

Only handsearching done as part of the Cochrane worldwide handsearching programme and uploaded to CENTRAL was included.

We searched reference lists of relevant articles and clinical trials in an attempt to identify any potential or additional studies.

We did not perform a separate search for adverse effects of interventions used, we considered adverse effects described in included studies only.

\section{Data collection and analysis}

\section{Selection of studies}

Three review authors independently assessed the titles and abstracts of studies resulting from the searches. All irrelevant records were excluded and only details of potential studies were noted. Full copies were obtained of all relevant and potentially relevant studies which appeared to meet the inclusion criteria, or when there were insufficient data in the title and abstract to make a clear decision. Studies not matching our inclusion criteria were excluded and their details and reasons for their exclusion were noted in the Characteristics of excluded studies table in Review Manager (RevMan) (Review Manager 2014).

\section{Data extraction and management}

Study details were entered into the Characteristics of included studies table. We collected outcome data using a predetermined form and entered them into RevMan. The review authors only included data if there was an independently reached consensus. All disagreements were resolved by discussion.

We extracted the following details.

- Study methods: method of allocation, masking of participants and outcomes.

- Participants: country of origin, sample size, age, sex, inclusion and exclusion criteria.

- Intervention: type of antibiotic.

- Control: analgesic, placebo or nil. 
- Outcomes: primary and secondary outcomes as described in the Types of outcome measures section of this review.

\section{Assessment of risk of bias in included studies}

Each of two review authors then graded the selected studies separately according to the domain-based evaluation described in the Cochrane Handbook for Systematic Reviews of Interventions 5.1.0 (updated March 2011) (Higgins 2011). The gradings were compared and any inconsistencies between the review authors were discussed and resolved.

The following domains were assessed as at 'low risk' of bias (i.e. plausible bias unlikely to seriously alter the results), 'unclear' (i.e. uncertain risk of bias, plausible risk of bias that raises some doubts about the results), or 'high risk' of bias (plausible bias that seriously weakens confidence in the results):

- sequence generation;

- allocation concealment;

- blinding (of participants, personnel and outcomes assessors);

- incomplete outcome data;

- selective outcome reporting; and

- other sources of bias.

We categorised and reported the overall risk of bias in the included study according to the following:

- low risk of bias (plausible bias unlikely to seriously alter the results) if all criteria were met;

- unclear risk of bias (plausible bias that raises some doubt about the results) if one or more criteria were assessed as unclear; or

- high risk of bias (plausible bias that seriously weakens confidence in the results) if one or more criteria were not met.

These assessments are reported for the included study in the Characteristics of included studies table.

\section{Measures of treatment effect}

The trialists in Nagle 2000 used sum of pain intensity difference (SPID) and sum of pain percussion intensity difference (SPPID) to assess between-group differences. Values were expressed as medians with interquartile ranges and were analysed using the Mann-Whitney-Wilcoxon test. Each patient was asked to rate their pain on a scale from 0 to $3(0=$ no pain; $1=$ mild pain, pain that was recognizable but not discomforting; $2=$ moderate pain, pain that was discomforting but bearable; 3 = severe pain, pain that caused considerable discomfort and was difficult to bear). Patients were asked to rate the pain to percussion using the same scale. SPID is defined as the sum of pain intensity differences weighted by the length of the interval since the previous observation. These assessments were made at wake-up time over the seven-day study period. We were unsuccessful in our attempts to contact the investigators to provide us with means or ranges of the minimum and maximum scores for SPID and SPPID, and therefore we were unable to calculate and present means, standard deviations and confidence intervals for these outcomes. These have been discussed narratively based on the data as reported in the study (see Effects of interventions).

We have presented the continuous outcomes on the original scale as reported in the study for our secondary outcome 'number of painkillers' together with their associated $95 \%$ confidence intervals (Cls). These data were analysed in RevMan (Review Manager 2014) using a random-effects model.

For future studies we will present continuous outcomes on the original scale as reported in each individual study. If similar outcomes were reported using different scales, we would convert these to standardized mean differences (SMD).

We will present dichotomous outcomes as risk ratios (RR), and if found significant, we would convert them to the number needed to treat (NNT) to find one success. We will report all outcomes' data with their associated $95 \% \mathrm{Cls}$ and analyse the data using a random-effects model in RevMan, with a general inverse variance (DerSimonian and Laird method), unless stated otherwise. In cases where only medians are presented with ranges, the mean is estimated by the median, and the variance using the range and the number of observations (Hozo 2005).

\section{Unit of analysis issues}

It is possible that studies included in future updates may present data from repeated observations on participants which may lead to unit of analysis errors, if so we will follow the advice provided in section 9.3.4 of the Cochrane Handbook for Systematic Reviews of Interventions (Higgins 2011).

\section{Dealing with missing data}

There were no missing data in the single included study. For future updates, if data are missing attempts will be made to contact the trial investigators.

\section{Assessment of heterogeneity}

There was only one single trial and therefore no assessments were made.

If further studies are included in future updates, we will assess clinical heterogeneity by examining the characteristics of the studies, the similarity between the types of participants, the interventions and outcomes as specified in the criteria for included studies. Statistical heterogeneity will be assessed using a $\mathrm{Chi}^{2}$ test and the $\mathrm{I}^{2}$ statistic where $\mathrm{I}^{2}$ values over $60 \%$ indicate moderate to substantial heterogeneity (Higgins 2011). If this could be explained by clinical reasoning and a coherent argument can be made for combining the studies, we will enter these into a meta-analysis. In cases where the heterogeneity could not be adequately explained, the data will not be pooled. A cut off $P$ value of $>0.10$ would be used to determine statistical significance.

\section{Assessment of reporting biases}

If a sufficient number $(>10)$ of trials investigating similar interventions are identified for inclusion in future updates of this review, publication bias will be assessed according to the recommendations on testing for funnel plot asymmetry as described in section 10.4.3.1 of the Cochrane Handbook for Systematic Reviews of Interventions (Higgins 2011). If asymmetry is identified, we will try to assess other possible causes and these will be explored in the discussion if appropriate.

\section{Data synthesis}

If further studies are included the following methods of data synthesis will apply. Data will be analysed using RevMan and 
reported according to Cochrane criteria. Pooling of data will only occur if the included studies have similar interventions involving similar participants. We will present risk ratios for outcomes and odds ratios for adverse effect outcomes. The risk ratio is the ratio of the risk of an event in the two groups whereas the odds ratio is the ratio of the odds of an adverse event in the intervention group to the odds of an event in the control group. Additionally, any data obtained from visual analogue scales and any categorical outcomes will be transformed into dichotomous data prior to analysis if appropriate. Risk ratios, the number needed to treat and their 95\% confidence intervals will be calculated for all dichotomous data.

\section{Subgroup analysis and investigation of heterogeneity}

If a sufficient number of studies with moderate to substantial heterogeneity (as defined above) are identified we will carry out subgroup analyses based on different antibiotics and dosing regimens.

\section{Sensitivity analysis}

We had expected to be able to conduct sensitivity analyses to assess the robustness of our review results by repeating the analysis with the following adjustments: exclusion of studies at high risk of bias and unpublished studies. However, as there was only a single trial that matched our inclusion criteria no sensitivity analyses were carried out.

\section{Summary of findings}

We developed a 'Summary of findings' table following GRADE methods (GRADE 2004) and using GRADEproGDT software
(GRADEpro GDT 2015) for the following outcomes listed according to priority.

- Patient-reported pain intensity (sum pain intensity differences and sum pain percussion intensity differences).

- Patient-reported pain relief.

- Total number of ibuprofen tablets.

- Total number of paracetamol (acetaminophen) + codeine tablets.

- Number of adverse events.

The certainty of the body of evidence was assessed with reference to the overall risk of bias of the included study, the directness of the evidence, the inconsistency of the results, the precision of the estimates, the risk of publication bias, and the magnitude of the effect. We categorised the certainty of the body of evidence for each outcome as high, moderate, low, or very low.

\section{RES U LTS}

\section{Description of studies}

\section{Results of the search}

The search strategy used in the first version of this review in 2005 identified 39 references of which all but four were excluded from further analysis. Full-text copies of these four papers were obtained for further assessment. Only one study (Nagle 2000) met the inclusion criteria and is included in the review. No additional studies were identified for inclusion based on subsequent updated searches in February 2009, September 2013, January 2016, or February 2019 (Figure 1). 
Figure 1. Study flow diagram.

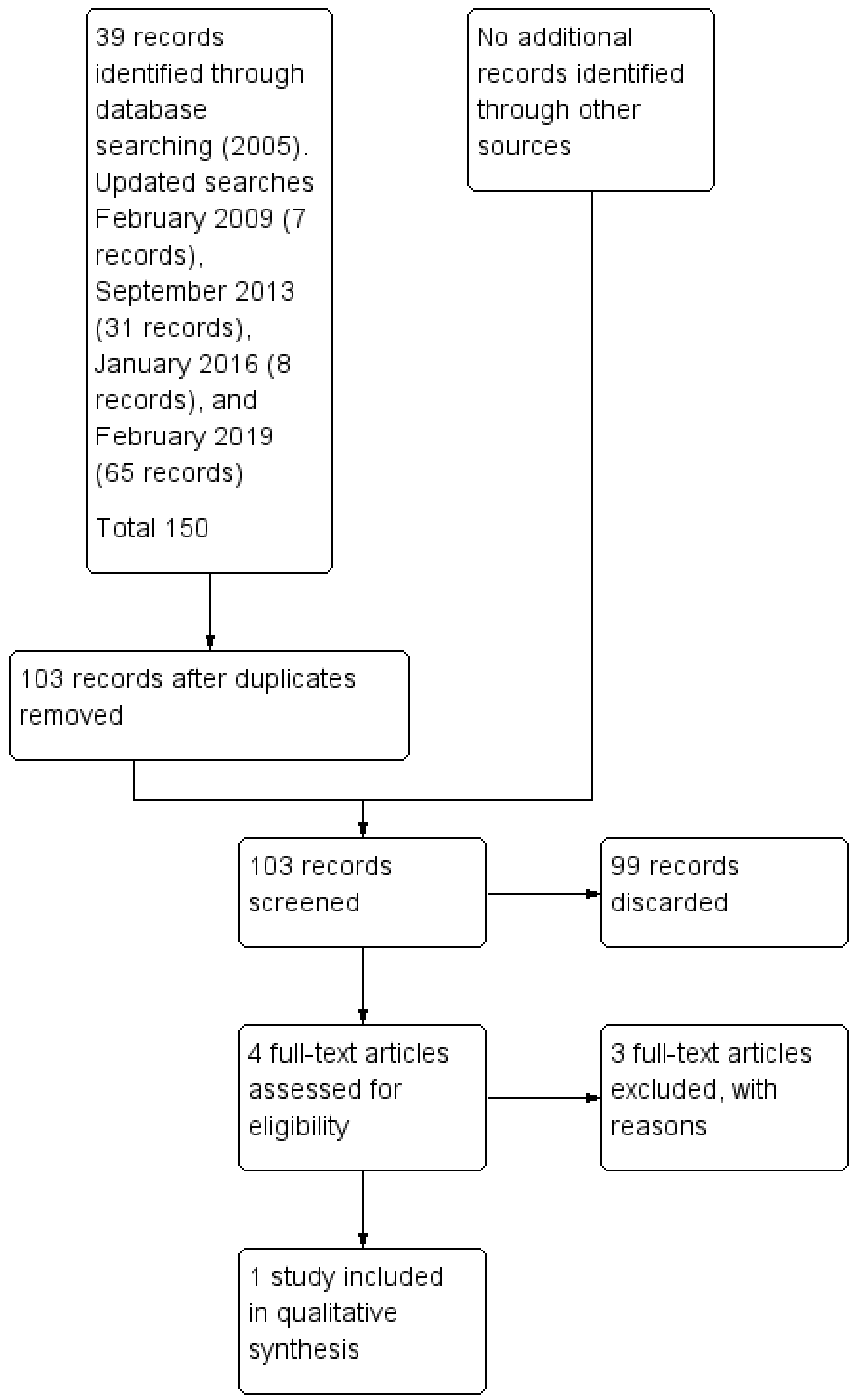




\section{Included studies}

\section{Methods}

Nagle 2000 is a randomised double-blind placebo-controlled clinical trial conducted in the emergency department of a university dental college in the USA.

\section{Participants and setting}

Forty adult patients, 17 male, 23 female, with an age range of 30 to 34 years who had presented as an emergency with spontaneous moderate to severe pain associated with a tooth, participated in this study. All of the teeth were vital and responsive to an electric pulp tester (EPT) and to Endo Ice and displayed percussion sensitivity. The diagnosis of irreversible pulpitis was confirmed by a radiographically widened periodontal ligament space (see Additional Table 1).

\section{Intervention}

Twenty participants were allocated to antibiotic and analgesic and 20 to placebo and analgesic. The participants received a sevenday oral dose ( 28 capsules each to be taken every six hours) of either penicillin $(500 \mathrm{mg})$ or a placebo control in which the participants and trialists were double-blinded. They also received a supply of pain medication consisting of ibuprofen $600 \mathrm{mg}$; paracetamol (acetaminophen) with codeine $30 \mathrm{mg}$ (Tylenol). No operative endodontic treatment was performed during the course of the study.

\section{Outcomes}

The primary outcome for this review was pain relief in the preoperative phase of irreversible pulpitis. Participants in this study were requested to complete a seven-day diary in which they recorded pain, percussion pain, and the quantity and type of pain medication taken. Pain was assessed using a short ordinal numerical scale graded from 0 to 3 (see Measures of treatment effect). Additionally, the patients were asked to use the same scale to rate pain on percussion which was achieved by tapping the affected tooth with a finger. The pain scale used in this trial had been used in previous pain studies which were referenced by the trialists of the included study.

The secondary outcome was the type and dose of pain medication required to achieve pain relief. The participants in this study were instructed to initially take one tablet of the ibuprofen every four to six hours as needed for pain and to take the Tylenol (two tablets every four to six hours) only if the ibuprofen did not relieve their pain. Each participant received a seven-day diary to record their symptoms and the number and type of pain medication taken. No assessments of adverse effects to either the antibiotics or analgesics were considered or reported by the investigators.

\section{Excluded studies}

Three studies were excluded: a systematic review (Matthews 2003) which included a potential trial (Henry 2001) which was subsequently excluded as it investigated the effect of antibiotics on postoperative endodontic pain. One trial (Fouad 1996) was excluded as it combined the interventions with immediate operative endodontic treatment. We excluded Nusstein 2003 because it was a retrospective non-experimental study, see Characteristics of excluded studies for further details.

\section{Risk of bias in included studies}

The single included study (Nagle 2000) met all of the criteria across all of the domains in Cochrane's tool for assessing the risk of bias, and therefore this study was considered to be at low risk of bias (plausible bias unlikely to seriously alter the results) (Figure 2). 
Figure 2. Risk of bias summary: review authors' judgements about each risk of bias item for each included study.

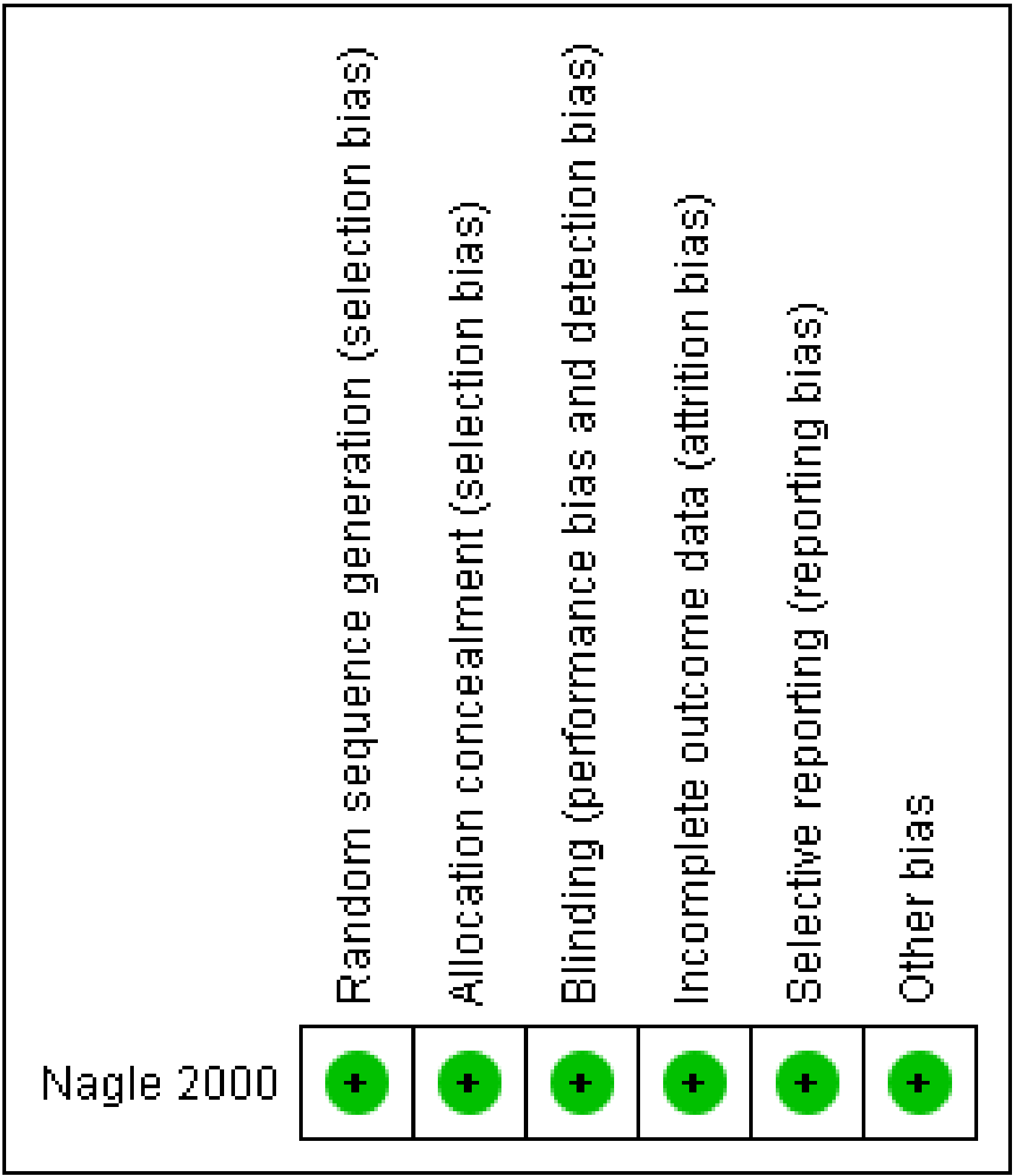

\section{Allocation}

\section{Sequence generation}

In this study the intervention (penicillin) and control (placebo) groups were assigned before the experiment by using four-digit numbers from a random number table. The method used to generate the allocation sequence was described in sufficient detail; therefore, this domain was judged as at low risk of bias.

\section{Allocation concealment}

To ensure adequate concealment only the random numbers were recorded on the data collection and postoperative diary sheets and 
it was unlikely that allocation could be foreseen and therefore this domain was judged as at low risk of bias.

\section{Blinding}

The measures used to blind study participants and personnel from knowledge of which intervention a participant received as well as blinding of outcomes assessors were described in sufficient detail. The medications were blinded, randomised, and packaged by a pharmacy. Each $500 \mathrm{mg}$ gelatin capsule of either penicillin or placebo was identical in form. The $500 \mathrm{mg}$ tablets of penicillin VK were ground into a powder and placed into the clear, unlabelled gelatin capsules. The white powder of the lactose placebo was indistinguishable from the white powder of the penicillin tablets when viewed through the capsule.

\section{Incomplete outcome data}

The report was complete and there were no missing data and this domain was judged as at low risk of bias.

\section{Selective reporting}

There was no evidence of selective outcome reporting and the outcomes listed in the methods section were comparable to the reported results. This was judged as at low risk of bias.

\section{Other potential sources of bias}

There was no evidence of other potential sources of bias in the report of the included trial.

\section{Effects of interventions}

See: Summary of findings for the main comparison Antibiotics for irreversible pulpitis

The single included study (Nagle 2000) did not provide sufficient data to perform a statistical analysis on the primary outcome and the only data presented are those which were published in the study. Unsuccessful attempts to obtain additional and individual level data from the trialists made it difficult to confirm the results presented in their study (see Measures of treatment effect).

\section{Oral penicillin in combination with analgesics versus placebo with analgesics}

\section{Primary outcome: patient-reported pain (intensity/duration) and pain relief}

Baseline data indicated that all of the participants that entered the study had moderate to severe pain (Additional Table 1). After the first day of the study the average pain rating decreased and remained quite stable over the following six days. This initial decrease in pain may be considered to be due to the effect of the analgesics which was sustained by the gradual and progressive necrosis of the pulp. However, at the end of the study period and at the commencement of operative endodontic treatment it was found that $75 \%$ of the teeth in the penicillin group and $80 \%$ in the placebo were still vital.

There was a close parallel distribution of the pain ratings in both the intervention and placebo groups over the seven days. The following data were presented as medians with their interquartile range. The in between-group differences in sum of pain intensity difference (SPID) for the penicillin group were $6.0 \pm 10.5$, and for placebo $6.0 \pm 9.5, P=0.776$. The sum of pain percussion intensity difference (SPPID) for the penicillin group was $3.5 \pm 7.5$ and placebo $2.0 \pm 7.0, P=0.290$, with differences as assessed by the MannWhitney-Wilcoxon test considered by the investigators of the study to be statistically significant at $P<0.05$ (Additional Table 2). (See Measures of treatment effect for additional information on these data.)

\section{Secondary outcome: type, dose and frequency of medication required for pain relief}

The number, percentage and average use and non-use of ibuprofen and Tylenol are summarised in Additional Table 3.

On both day one and day two only one participant did not take either one or other of the analgesic medications. The number not taking any medication increased to three to four (15\% to $20 \%)$ on day three, and two to six (10\% to $30 \%)$ on day four. On the fifth to seventh days only four to seven (20\% to $35 \%$ ) did not take any additional pain medication. At day seven, $20 \%$ of the penicillin group and $35 \%$ of the placebo group took no additional analgesics. There was no significant difference in the mean total number of ibuprofen tablets over the study period: 9.20 (standard deviation (SD) 6.02) in the penicillin group versus 9.60 (SD 6.34) in the placebo group; mean difference -0.40 (95\% confidence interval $(\mathrm{Cl})-4.23$ to 3.43; $P=0.84)$. The same was true for the mean total number of Tylenol tablets: 6.90 (SD 6.87) in the penicillin group versus 4.45 (SD 4.82) in the placebo group; mean difference 2.45 (95\% Cl -1.23 to $6.13 ; P=0.19$ ). There was insufficient evidence to determine whether penicillin reduced the quantity of analgesic medication or not.

\section{Secondary outcome: adverse events}

Not assessed.

\section{DISCUSSION}

\section{Summary of main results}

The results of this well constructed but underpowered trial of 20 participants in each study arm indicate that the administration of penicillin did not appear to significantly $(P>0.05)$ reduce either the pain perception, the percussion perception, or the quantity of analgesic medication required by patients with irreversible pulpitis. Our secondary outcome regarding adverse events or reactions was not addressed. The certainty of the evidence was rated low for the different outcomes. For further details see Summary of findings for the main comparison.

The significance of the relatively common occurrence of toothache, the prevalence of inappropriate prescribing of antibiotics with the potential for producing antibiotic resistance and patient sensitisation cannot be underestimated. It was somewhat disappointing to see that only one single trial matched our inclusion criteria.

\section{Overall completeness and applicability of evidence}

The single included study (Nagle 2000) provides insufficient evidence that the administration of antibiotics is effective in relieving the pain from irreversible pulpitis. However, although we consider that the population, intervention, comparator to the intervention, and outcome of interest satisfy the clinical question of our review, the lack of further research since this study was conducted, which is still highly desirable, would appear to indicate that there is a wider acceptance that the 'standard of care' 
and appropriate management strategy for irreversible pulpitis is immediate extirpation of the pulp.

\section{Quality of the evidence}

The certainty of the evidence as summarised in Summary of findings for the main comparison was rated as low. The most important reasons for downgrading for each outcome were: imprecision, mainly due to low sample size and the $95 \%$ confidence interval included no effect and the upper or lower confidence limit crossed the minimal important difference.

\section{Limitations in study design and implementation}

We did not identify any limitations in either the design or implementation of the study (Figure 2). However, adverse events were not addressed in this study.

\section{Indirectness of the evidence}

Although limited to a single study, the evidence can be directly generalized to the clinical scenario of the presentation of irreversible pulpitis.

\section{Inconsistency of the results}

The single included study did not allow any assessment of inconsistency of results.

\section{Imprecision of the results}

The single study with a low sample size included in this review provided limited amounts of data. Our primary outcome was downgraded due to small sample size, and due to the sparse data we were unable to further evaluate the imprecision of the results. However, for our secondary outcome we downgraded twice as the confidence intervals included no effect and both the upper and lower confidence limit crossed the minimal important difference.

\section{Publication bias}

Although it would be reasonable to assume that the comprehensive searches will have identified all existing randomised controlled trials, and thereby helped to limit bias in the conduct of this review, the absence of any published trials over the last 10 years creates a measure of uncertainty that there may be further and as yet unpublished studies which might add to the overall evidence.

\section{Potential biases in the review process}

We made every attempt to limit bias in the review process by ensuring a comprehensive search for potentially eligible studies. The authors' independent assessments of eligibility of studies for inclusion in this review minimised the potential for selection bias. The effects of language bias on the identification and selection of studies for inclusion in a systematic review is widely recognised; therefore, we ensured that language of publication was not used as an exclusion criterion.

\section{Agreements and disagreements with other studies or reviews}

Our electronic searches did identify two systematic reviews (Aminoshariae 2016; Matthews 2003) which offered strong confirmatory evidence that in the absence of systemic complications e.g. fever, lymphadenopathy, cellulitis or in immunocompromised patients, antibiotics alone have no place in the management of localised acute apical abscess. Furthermore, they stated that although the pain from acute apical abscess is as a result of an infective process, the infection is localised and that even in this terminal stage of irreversible pulpitis the use of antibiotics as a sole or concomitant therapy remains questionable.

In our search for additional studies and reviews, we also examined several clinical references and sources for guidelines and systematic reviews: Agency for Healthcare Research and Quality (www.ahrq.gov), National Guidelines Clearinghouse (www.guideline.gov), National Institute for Health and Care Excellence (www.nice.org.uk), Scottish Intercollegiate Guidelines Network (www.sign.ac.uk/index.html), UK Database of Uncertainties about the Effects of Treatments (www.library.nhs.uk/ duets), and UpToDate (www.uptodate.com/home). It was surprising to find that the majority did not address this clinical topic or provided very limited useful or current information that could aid clinical decision-making.

\section{AUTHORS' CONCLUSIONS}

\section{Implications for practice}

This review illustrates that there is insufficient evidence to determine whether antibiotics reduce pain or not when compared to not having antibiotics. The certainty of the evidence for the different outcomes was low, mainly due to imprecision of the data. Although there was a paucity of high-certainty evidence to guide clinical practice, the prescribing of antibiotics for irreversible pulpitis should not be seen as a substitute for immediate pulpectomy which is now widely accepted as the 'standard of care.'

\section{Implications for research}

The results of this Cochrane Review confirm the necessity for further larger sample and methodologically sound trials that can help provide additional evidence as to whether antibiotics can affect treatment outcomes for irreversible pulpitis.

Any future randomised controlled trials must be welldesigned, well-conducted, and adequately delivered with subsequent reporting, including high-quality descriptions of all aspects of methodology. Reporting should conform to the CONSORT statement (www.consort-statement.org) which will enable appraisal and interpretation of results, and accurate judgements to be made about the risk of bias, and the overall certainty of the evidence.

Although it is uncertain whether reported quality mirrors actual study conduct, it is noteworthy that studies with unclear methodology have been shown to produce biased estimates of treatment effects (Schulz 1995).

For further research recommendations based on the EPICOT (evidence, population, intervention, comparison, outcomes, and time) format (Brown 2006), see Additional Table 4. However, it may be more appropriate for future research to concentrate on pain control rather than prescription of antibiotics.

\section{ACKN OWLEDGEMEN TS}

We would like to express our gratitude to the following: Anne Littlewood the Information Specialist of Cochrane Oral Health who executed the electronic searches for our review. To Emma Tavender who provided guidance on an earlier version of this review and Luisa Fernandez Mauleffinch who assisted with updating and copy 
edited this review. To Scott McLanahan, Professor of Endodontics at the Naval Postgraduate Dental School, Bethesda MD USA, the author of an article on this topic which provided the starting point for this review and who kindly agreed to continue providing advice. Our thanks are also due to Mohammed Ghali Rashid, the reference and serials librarian and ILL service co-ordinator at the Arabian
Gulf University Kingdom of Bahrain, who obtained some of the initial background references for this review. We would also like to acknowledge the contribution of four previous review authors James Keenan,Tim Newton, Jassim Hassan Al-Langawi, and Allan G Farman. 
RE FE RE N CES

\section{References to studies included in this review}

Nagle 2000 \{published data only\}

Nagle D, Reader A, Beck M, Weaver J. Effect of systemic penicillin on pain in untreated irreversible pulpitis. Oral Surgery, Oral Medicine, Oral Pathology, Oral Radiology, and Endodontics 2000;90(5):636-40.

\section{References to studies excluded from this review}

Fouad 1996 \{published data only\}

Fouad AF, Rivera EM, Walton RE. Penicillin as a supplement in resolving the localized acute apical abscess. Oral Surgery, Oral Medicine, Oral Pathology, Oral Radiology, and Endodontics 1996;81(5):590-5.

\section{Henry 2001 \{published data only\}}

Henry M, Reader A, Beck M. Effect of penicillin on postoperative endodontic pain and swelling in symptomatic necrotic teeth. Journal of Endodontics 2001;27(2):117-23.

\section{Nusstein 2003 \{published data only\}}

Nusstein JM, Beck M. Comparison of preoperative pain and medication use in emergency patients presenting with irreversible pulpitis or teeth with necrotic pulps. Oral Surgery, Oral Medicine, Oral Pathology, Oral Radiology, and Endodontics 2003;96(2):207-14.

\section{Additional references}

\section{Agnihotry 2014}

Agnihotry A, Al-Langawi JH, Khanna A. Inappropriate use of antibiotics in dentistry. Journal of the Bahrain Medical Society 2014;25(1):55-6.

\section{Agnihotry 2014a}

Agnihotry A, Al-Langawi J, Fedorowicz Z, Outhouse T. Improving the 'Implications for Practice/Research' section of a Cochrane Review using a survey questionnaire. 22nd Cochrane Colloquium; 2014 Sept 21-26; Hyderabad, India. 2014.colloquium.cochrane.org/: Cochrane, 2014. [P192]

\section{Aminoshariae 2016}

Aminoshariae A, Kulild JC. Evidence-based recommendations for antibiotic usage to treat endodontic infections and pain: a systematic review of randomized controlled trials. Journal of the American Dental Association 2016;147(3):186-91.

\section{Beacher 2015}

Beacher N, Sweeney MP, Bagg J. Dentists, antibiotics and Clostridium difficile-associated disease. British Dental Journal 2015;219(6):275-9.

\section{Bergenholtz 1990}

Bergenholtz G. Pathogenic mechanisms in pulpal disease. Journal of Endodontics 1990;16(2):98-101.

\section{Brown 2006}

Brown P, Brunnhuber K, Chalkidou K, Chalmers I, Clarke M, Fenton $\mathrm{M}$, et al. How to formulate research questions. BMJ 2006;333(7572):804-6.

\section{Bye 2017}

Bye M, Whitten T, Holzbauer S. Antibiotic prescribing for dental procedures in community-associated Clostridium difficile cases, Minnesota, 2009-2015. Open Forum Infectious Diseases 2017;4(Suppl 1):S1.

\section{CDC 2008}

US Centers for Disease Control and Prevention. About antibiotic resistance. www.cdc.gov/drugresistance/community/anitbioticresistance-faqs.htm 2008.

\section{Chopra 2014}

Chopra R, Merali R, Paolinelis G, Kwok J. An audit of antimicrobial prescribing in an acute dental care department. Primary Dental Journal 2014;3(4):24-9.

\section{Cope 2016}

Cope AL, Francis NA, Wood F, Chestnutt IG. Antibiotic prescribing in UK general dental practice: a cross-sectional study. Community Dentistry and Oral Epidemiology 2016;44(2):145-53.

\section{Cope 2018}

Cope AL, Francis N, Wood F, Chestnutt IG. Systemic antibiotics for symptomatic apical periodontitis and acute apical abscess in adults. Cochrane Database of Systematic Reviews 2018, Issue 9. [DOI: 10.1002/14651858.CD010136.pub3]

\section{Dar-Odeh 2010}

Dar-Odeh NS, Abu-Hammad OA, Al-Omiri MK, Khraisat AS, Shehabi AA. Antibiotic prescribing practices by dentists: a review. Therapeutics and Clinical Risk Management 2010;6:301-6

\section{GRADE 2004}

GRADE Working Group. Grading quality of evidence and strength of recommendations. BMJ 2004;328(7454):1490.

\section{GRADEpro GDT 2015 [Computer program]}

McMaster University (developed by Evidence Prime). GRADEpro GDT. Version accessed 1 February 2016. Hamilton (ON): McMaster University (developed by Evidence Prime), 2015.

\section{Hahn 1991}

Hahn CL, Falkler WA, Minah GE. Microbiological studies of carious dentine from human teeth with irreversible pulpitis. Archives of Oral Biology 1991;36(2):147-53.

\section{Hargreaves 2015}

Hargreaves K, Berman L. Diagnosis. Cohen's Pathways of the Pulp Expert Consult. 11th Edition. Mosby, Elsevier, 2015:29. 


\section{Higgins 2011}

Higgins JP, Green S, editor(s). Cochrane Handbook for Systematic Reviews of Interventions Version 5.1.0 (updated March 2011). The Cochrane Collaboration, 2011. Available from handbook.cochrane.org.

\section{Hozo 2005}

Hozo SP, Djulbegovic B, Hozo I. Estimating the mean and variance from the median, range, and the size of a sample. $B M C$ Medical Research Methodology 2005;5:13.

\section{Mainjot 2009}

Mainjot A, D'Hoore W, Vanheusden A, Van Nieuwenhuysen JP. Antibiotic prescribing in dental practice in Belgium. International Endodontic Journal 2009;42(12):1112-7.

\section{Matthews 2003}

Matthews DC, Sutherland S, Basrani B. Emergency management of acute apical abscesses in the permanent dentition: a systematic review of the literature. Journal of the Canadian Dental Association 2003;69(10):660.

\section{O'Neill 2016}

O'Neill J. Tackling drug-resistant infections globally: final report and recommendations. The review on antimicrobial resistance. amr-review.org/sites/default/files/160518_Final\%20paper_with \%20cover.pdf 2016:17-20.

\section{Onkunseri 2012}

Okunseri C, Okunseri E, Thorpe JM, Xiang Q, Szabo A. Patient characteristics and trends in nontraumatic dental condition visits to emergency departments in the United States. Clinical, Cosmetic and Investigational Dentistry 2012;16(4):1-7.

\section{Palmer 2003}

Palmer NA. Revisiting the role of dentists in prescribing antibiotics. Dental Update 2003;30(10):570-4.

\section{Review Manager 2014 [Computer program]}

Nordic Cochrane Centre, The Cochrane Collaboration. Review Manager 5 (RevMan 5). Version 5.3. Copenhagen: Nordic Cochrane Centre, The Cochrane Collaboration, 2014.

\section{Rodriguez-Núñez 2009}

Rodriguez-Núñez A, Cisneros-Cabello R, Velasco-Ortega E, Llamas-Carreras JM, Tórres-Lagares D, Segura-Egea JJ. Antibiotic use by members of the Spanish Endodontic Society. Journal of Endodontics 2009;35(9):1198-203.

\section{Schulz 1995}

Schulz KF, Chalmers I, Hayes RJ, Altman DG. Empirical evidence of bias. Dimensions of methodological quality associated with estimates of treatment effects in controlled trials. Journal of the American Medical Association 1995;273(5):408-12.

\section{SDCEP 2016}

Scottish Dental Clinical Effectiveness Programme (SDCEP). Drug prescribing for dentistry. Dental Clinical Guidance. 3rd Edition. Dundee: Scottish Dental Clinical Effectiveness Programme, 2016:27-38

\section{Segura-Egea 2010}

Segura-Egea JJ, Velasco-Ortega E, Torres-Lagares D, VelascoPonferrada MC, Monsalve-Guil L, Llamas-Carreras JM. Pattern of antibiotic prescription in the management of endodontic infections amongst Spanish oral surgeons. International Endodontic Journal 2010;43(4):342-50.

\section{Segura-Egea 2018}

Segura-Egea JJ, Gould K, Şen B, HakanJonasson P, Cotti E, Mazzoni A, Sunay H, Tjäderhane L, Dummer PMH. European Society of Endodontology position statement: the use of antibiotics in endodontics. International Endodontic Journal 2018;51(1):20-25

\section{SMAC 1997}

Standing Medical Advisory Committee (SMAC). The path of least resistance. London: Standing Medical Advisory Committee SubGroup on Antimicrobial Resistance, Department of Health; 1997.

\section{Soames 1998}

Soames JV, Southam JC. Oral Pathology. 3rd Edition. Oxford: Oxford University Press, 1998:51-70.

\section{Steele 2011}

Steele, J, Pitts, N, Fuller E, Treasure E. Urgent conditions - a report from the Adult Dental Health Survey 2009; March 2011. Available at files.digital.nhs.uk/publicationimport/pub01xxx/ pub01086/adul-dent-heal-surv-summ-them-the3-2009rep5.pdf.

\section{Tronstad 1991}

Tronstad L. The endodontium. Clinical Endodontics. New York: Thieme, 1991:1-31.

\section{Turner 2015}

Turner PJ, Gowland MH, Sharma V, lerodiakonou D, Harper N, Garcez T, et al. Increase in anaphylaxis-related hospitalizations but no increase in fatalities: an analysis of United Kingdom national anaphylaxis data, 1992-2012. Journal of Allergy and Clinical Immunology 2015;135(4):956-63.

\section{Walton 2009}

Walton RE. Endodontics: Principles and Practice. 4th Edition. St Louis, Missouri: Saunders Elsevier, 2009.

\section{WHO 2018}

World Health Organization. Antimicrobial resistance; February 2018. Available at www.who.int/news-room/fact-sheets/detail/ antimicrobial-resistance.

\section{Yingling 2002}

Yingling NM, Byrne BE, Hartwell GR. Antibiotic use by members of the American Association of Endodontists in the year 2000: report of a national survey. Journal of Endodontics 2002;28(5):396-404. 


\section{References to other published versions of this review}

\section{Agnihotry 2016}

Agnihotry A, Fedorowicz Z, van Zuuren EJ, Farman AG, Al-Langawi JH. Antibiotic use for irreversible pulpitis. Cochrane Database of Systematic Reviews 2016, Issue 2. [DOI: 10.1002/14651858.CD004969.pub4]

\section{Fedorowicz 2005}

Fedorowicz Z, Keenan JV, Farman AG, Newton T. Antibiotic use for irreversible pulpitis. Cochrane Database of Systematic Reviews 2005, Issue 2. [DOI: 10.1002/14651858.CD004969.pub2]

\section{CHARACTERISTICS OF STUDIES}

Characteristics of included studies [ordered by study ID]

\section{Fedorowicz 2013}

Fedorowicz Z, van Zuuren EJ, Farman AG, Agnihotry A, Al-Langawi JH. Antibiotic use for irreversible pulpitis.

Cochrane Database of Systematic Reviews 2013, Issue 12. [DOI: 10.1002/14651858.CD004969.pub3]

\section{Keenan 2004}

Keenan JV, Farman AG, Fedorowicz Z, Newton JT. Antibiotic use for irreversible pulpitis. Cochrane Database of Systematic Reviews 2004, Issue 4. [DOI: 10.1002/14651858.CD004969]

\section{Nagle 2000}

Methods

Prospective randomised double-blind trial in the USA. Before the experiment, patient groups (penicillin or placebo) were assigned by using 4-digit numbers from a random number table. Only the random numbers were recorded on the data collection and postoperative diary sheets to blind the experiment. The medications were blinded, randomised, and packaged by a pharmacy.

Participants Adults: (40) 17 male, 23 female. Mean age and standard deviation (SD) in the penicillin group 30 (9.8), placebo group 34 (11.6).

2 groups of 20: penicillin group 7 women and 13 men, placebo 16 women and 4 men.

Inclusion criteria:

- participants in "good health",

- clinical diagnosis of irreversible pulpitis (spontaneous moderate/severe pain),

- percussion sensitivity,

- tooth vital to electric pulp tester (EPT) and painful response to Endo Ice,

- radiographically widened periodontal ligament space.

Exclusion criteria:

- tooth not responsive to EPT,

- participants taking antibiotics or in the preceding 30 days.

Oral penicillin or placebo control (lactose) and all patients received analgesics.

7-day oral dose 500 mg 6 hourly; penicillin (Penicillin VK; Wyeth Laboratories, Philadelphia, Pa) or a placebo control (lactose).

Analgesics: 600 mg ibuprofen (Motrin; HN Norton Co, Shreveport, La); paracetamol (acetaminophen) with 30 mg of codeine (Tylenol No 3; McNeil Consumer Products, Fort Washington, Pa).

\section{Risk of bias}

\begin{tabular}{lll}
\hline Bias & Authors' judgement & Support for judgement \\
\hline $\begin{array}{ll}\text { Random sequence genera- } \\
\text { tion (selection bias) }\end{array}$ & Low risk & $\begin{array}{l}\text { Quote: "Before the experiment, patient groups (penicillin or placebo) were as- } \\
\text { signed by using 4-digit numbers from a random number table." } \\
\text { Comment: probably done. }\end{array}$
\end{tabular}


Nagle 2000 (Continued)

Allocation concealment Low risk Quote: "Only the random numbers were recorded on the data collection and (selection bias) postoperative diary sheets to blind the experiment." "The medications were blinded, randomized, and packaged by a pharmacy."

Comment: central randomisation, probably done.

\section{Blinding (performance Low risk Participants/healthcare providers.}

bias and detection bias)

All outcomes

Quote: "Each 500-mg gelatin capsule of either penicillin or placebo was identical in form. The 500-mg tablets of penicillin VK were ground into a powder and placed into the clear, unlabeled gelatin capsules. The white powder of the lactose placebo was indistinguishable from the white powder of the penicillin tablets when viewed through the capsule."

Comment: probably done.

Outcomes assessors and data analysts.

The outcomes were self-assessed and as the caregivers were blinded, this was probably done.

Incomplete outcome data Low risk Outcome data were complete for all of the participants.
(attrition bias)

All outcomes

Comment: we judged this as at low risk of bias.

Selective reporting (re- Low risk
porting bias)
porting bias)

No evidence of selective choice of data for outcomes. Outcomes listed in the methods section comparable to the reported results.

Comment: we judged this as at low risk of bias.

Other bias Low risk

Quote: "Supported by research funding from the Endodontic Graduate Student Research Fund and the Steve Goldberg Memorial Fund, The Ohio State University."

Comment: appears to be free of other bias.

Characteristics of excluded studies [ordered by study ID]

\begin{tabular}{ll}
\hline Study & Reason for exclusion \\
\hline Fouad 1996 & $\begin{array}{l}\text { This study combined antibiotic or placebo or neither as an adjunct to operative endodontic treat- } \\
\text { ment in resolving the acute apical abscess. }\end{array}$ \\
\hline Henry 2001 & This study combined antibiotic as an adjunct to endodontic treatment. \\
\hline Nusstein 2003 & This study was a retrospective non-experimental study. \\
\hline
\end{tabular}

ADDITIONAL TABLES

Table 1. Baseline pain and percussion values for penicillin and placebo groups

\begin{tabular}{lcc}
\hline & Penicillin & Placebo \\
\hline Initial pain (median \& interquartile range) & $2.00 \pm 0.00$ & $2.00 \pm 1.00$ \\
\hline Initial percussion pain (median \& interquartile range) & $2.00 \pm 0.50$ & $2.00 \pm 1.00$ \\
\hline \hline
\end{tabular}

Antibiotic use for irreversible pulpitis (Review) 
Table 1. Baseline pain and percussion values for penicillin and placebo groups (Continued)

\begin{tabular}{lll} 
Pain ratings: moderate & $65 \%$ & $80 \%$ \\
\hline Pain ratings: severe & $35 \%$ & $20 \%$ \\
\hline Percussion pain ratings: mild & $20 \%$ & $25 \%$ \\
\hline Percussion pain ratings: moderate & $50 \%$ & $65 \%$ \\
\hline Percussion pain ratings: severe & $30 \%$ & $10 \%$ \\
\hline
\end{tabular}

Table 2. Sum of pain and percussion pain intensity difference

\begin{tabular}{llll}
\hline & Penicillin & Placebo & P value \\
\hline $\begin{array}{l}\text { Sum of pain intensity difference (median and interquartile } \\
\text { range) }\end{array}$ & $6.0 \pm 10.5$ & $6.0 \pm 9.5$ & 0.776 \\
\hline $\begin{array}{l}\text { Sum of percussion pain intensity difference (median and in- } \\
\text { terquartile range) }\end{array}$ & $3.5 \pm 7.5$ & $2.0 \pm 7.0$ & 0.290 \\
\hline
\end{tabular}

Table 3. Use of pain medication for penicillin and placebo groups (number and quantity)

\begin{tabular}{|c|c|c|c|}
\hline Day & Number ibuprofen & Number Tylenol & $\begin{array}{l}\text { Nil pain medica- } \\
\text { tion }\end{array}$ \\
\hline \multicolumn{4}{|l|}{ Day 1} \\
\hline Penicillin & $17(85 \%)$ & $10(50 \%)$ & $1(5 \%)$ \\
\hline Number of tablets & 33 & 21 & 0 \\
\hline Placebo & $16(80 \%)$ & $8(40 \%)$ & 0 \\
\hline Number of tablets & 28 & 11 & 0 \\
\hline \multicolumn{4}{|l|}{ Day 2} \\
\hline Penicillin & $17(85 \%)$ & $10(50 \%)$ & 0 \\
\hline Number of tablets & 30 & 28 & 0 \\
\hline Placebo & $16(80 \%)$ & $9(45 \%)$ & $1(5 \%)$ \\
\hline Number of tablets & 31 & 18 & 0 \\
\hline \multicolumn{4}{|l|}{ Day 3} \\
\hline Penicillin & $13(65 \%)$ & $9(45 \%)$ & $4(20 \%)$ \\
\hline Number of tablets & 27 & 20 & 0 \\
\hline Placebo & $15(75 \%)$ & $8(40 \%)$ & $3(15 \%)$ \\
\hline
\end{tabular}


Table 3. Use of pain medication for penicillin and placebo groups (number and quantity) (Continued)

Number of tablets

28

\section{Day 4}

\begin{tabular}{|c|c|c|c|}
\hline Penicillin & $12(60 \%)$ & $9(45 \%)$ & $6(30 \%)$ \\
\hline Number of tablets & 24 & 23 & 0 \\
\hline Placebo & $17(85 \%)$ & $5(25 \%)$ & $2(10 \%)$ \\
\hline Number of tablets & 28 & 8 & 0 \\
\hline \multicolumn{4}{|l|}{ Day 5} \\
\hline Penicillin & $12(60 \%)$ & $8(40 \%)$ & $7(35 \%)$ \\
\hline Number of tablets & 21 & 15 & 0 \\
\hline Placebo & $16(80 \%)$ & $7(35 \%)$ & $3(15 \%)$ \\
\hline Number of tablets & 32 & 11 & 0 \\
\hline \multicolumn{4}{|l|}{ Day 6} \\
\hline Penicillin & $13(65 \%)$ & $8(40 \%)$ & $5(25 \%)$ \\
\hline Number of tablets & 24 & 15 & 0 \\
\hline Placebo & $13(65 \%)$ & $6(30 \%)$ & $6(30 \%)$ \\
\hline Number of tablets & 24 & 13 & 0 \\
\hline \multicolumn{4}{|l|}{ Day 7} \\
\hline Penicillin & $14(70 \%)$ & $10(50 \%)$ & $4(20 \%)$ \\
\hline Number of tablets & 25 & 16 & 0 \\
\hline Placebo & $11(55 \%)$ & $7(35 \%)$ & $7(35 \%)$ \\
\hline Number of tablets & 20 & 14 & 0 \\
\hline
\end{tabular}

Table 4. Research recommendations based on a gap in the evidence of the effects of antibiotics for irreversible pulpitis

\begin{tabular}{lll}
\hline Core elements & Issues to consider & Status of research for this review \\
\hline Evidence $(\mathrm{E})$ & $\begin{array}{l}\text { What is the current state of the evi- } \\
\text { dence? }\end{array}$ & This systematic review identified 1 randomised controlled trial \\
\hline Population $(\mathrm{P})$ & $\begin{array}{l}\text { Diagnosis, disease stage, comor- } \\
\text { bidity, risk factors, gender, age, } \\
\text { ethnic group, specific inclusion or } \\
\text { exclusion criteria, clinical setting }\end{array}$ & $\begin{array}{l}\text { Inclusion criteria } \\
\text { Adult patients }>18 \text { years with a single tooth with a clinical diag- } \\
\text { nosis of irreversible pulpitis }\end{array}$
\end{tabular}


Table 4. Research recommendations based on a gap in the evidence of the effects of antibiotics for irreversible pulpitis (Continued)

\author{
Exclusion criteria
}

- If pulpectomy is to be provided immediately

\begin{tabular}{|c|c|c|}
\hline Intervention (I) & $\begin{array}{l}\text { Type, frequency, dose, duration, } \\
\text { prognostic factor }\end{array}$ & $\begin{array}{l}\text { Any systemic antibiotic at any dosage and any analgesic at any } \\
\text { dosage prescribed in the acute preoperative phase of irreversible } \\
\text { pulpitis }\end{array}$ \\
\hline Comparison (C) & $\begin{array}{l}\text { Type, frequency, dose, duration, } \\
\text { prognostic factor }\end{array}$ & $\begin{array}{l}\text { Placebo and any analgesic, at any dosage, prescribed in the acute } \\
\text { preoperative phase of irreversible pulpitis }\end{array}$ \\
\hline Outcome (0) & $\begin{array}{l}\text { Which clinical or patient-related } \\
\text { outcomes will the researcher need } \\
\text { to measure, improve, influence, } \\
\text { or accomplish? Which methods of } \\
\text { measurement should be used? }\end{array}$ & $\begin{array}{l}\text { - Patient-reported pain (intensity/duration) and pain relief mea- } \\
\text { sured on a categorical scale in the preoperative phase of irre- } \\
\text { versible pulpitis } \\
\text { - Any adverse effects related to any clinically diagnosed hypersen- } \\
\text { sitivity or other reactions to either the antibiotics or analgesics } \\
\text { - Type, dose and frequency of medication required for pain relief }\end{array}$ \\
\hline Time stamp (T) & $\begin{array}{l}\text { Date of literature search or recom- } \\
\text { mendation }\end{array}$ & 18 February 2019 \\
\hline Study type & $\begin{array}{l}\text { What is the most appropriate } \\
\text { study design to address the pro- } \\
\text { posed question? }\end{array}$ & $\begin{array}{l}\text { - Randomised controlled trial (adequately powered/multicentred) } \\
\text { - Methods: concealment of allocation sequence } \\
\text { - Blinding: participants, trialists, outcomes assessors, data analysts } \\
\text { - Setting: hospital/university or general practice with adequate fol- } \\
\text { low-up }\end{array}$ \\
\hline
\end{tabular}

\title{
AP PEN DICES
}

\section{Appendix 1. Cochrane Oral Health's Trials Register search strategy}

Cochrane Oral Health's Trials Register is available via the Cochrane Register of Studies. For information on how the register is compiled, see oralhealth.cochrane.org/trials.

From September 2013, searches of Cochrane Oral Health's Trials Register were conducted using the Cochrane Register of Studies and the search strategy below:

\#1 ((anti-bacterial-agents OR penicillin* OR amoxicillin* OR erythromycin* OR antibiotic OR anti-biotic OR antibacterial* OR antibacterial*)) AND (INREGISTER)

$\# 2$ (pulpectom*)

\#3 \#1 and \#2

Previous searches for this review were conducted using Cochrane Oral Health's Trials Register via the Procite software:

((anti-bacterial-agents OR penicillin* OR amoxicillin* OR erythromycin* OR antibiotic OR anti-biotic OR antibacterial* OR anti-bacterial*) AND (pulpectom*))

\section{Appendix 2. Cochrane Central Register of Controlled Trials (CENTRAL) search strategy}

\author{
1. ANTI-BACTERIAL AGENTS \\ 2. PENICILLINS \\ 3. antibiotic ${ }^{*}$ OR anti-biotic ${ }^{*}$ \\ 4. (antibacterial agent ${ }^{\star}$ OR anti-bacterial agent ${ }^{\star}$ ) \\ 5. antibacterial ${ }^{\star}$ OR anti-bacterial ${ }^{\star}$ \\ 6. (penicillin* or amoxicillin or erythromycin) \\ 7. 1 OR 2 OR 3 OR 4 OR 5 OR 6
}




\section{PULPECTOMY \\ 9. pulpectom ${ }^{\star}$ \\ 10. (\#8 or \#9) \\ 11.(\#7 and \#10)}

\section{Appendix 3. MEDLINE (Ovid) search strategy}

1. Anti-Bacterial Agents/

2. PENICILLINS/

3. (antibiotic\$ or anti-biotic\$).mp.

4. anti-bacterial-agent\$.mp.

5. antibacterial agent\$.mp.

6. (antibacterial\$ or anti-bacterial\$).mp.

7. (penicillin\$ or amoxicillin\$ or erythromycin\$).mp.

8. or/1-7

9. PULPECTOMY/

10. pulpect\$.mp.

11. or/9-10

12. 8 and 11

\section{Appendix 4. Embase (Ovid) search strategy}

1. Antibiotic Agent/

2. PENICILLIN DERIVATIVE/

3. (antibiotic\$ or anti-biotic\$).mp.

4. anti-bacterial-agent\$.mp.

5. antibacterial agent\$.mp.

6. (antibacterial\$ or anti-bacterial\$).mp.

7. (penicillin\$ or amoxicillin\$ or erythromycin\$).mp.

8. or/1-7

9. pulpectom\$.mp.

10. 8 and 9

\section{Appendix 5. US National Institutes of Health Ongoing Trials Register (ClinicalTrials.gov) and World Health Organization International Clinical Trials Registry Platform search strategy}

pulpectomy and antibiotics

pulpectomy and antibacterial

pulpectomy and penicillin

pulpectomy and amoxicillin

\section{WHAT'S NEW}

\begin{tabular}{lll}
\hline Date & Event & Description \\
\hline 1 July 2019 & Review declared as stable & $\begin{array}{l}\text { No new studies found for inclusion since review was first pub- } \\
\text { lished in 2005. This Cochrane Review will not be updated until a } \\
\text { substantial body of evidence on the topic becomes available. If } \\
\text { trials are conducted and found eligible for inclusion in the future, } \\
\text { the review would then be updated accordingly. }\end{array}$ \\
\end{tabular}

\section{H IS T ORY}

Protocol first published: Issue 4, 2004

Review first published: Issue 2, 2005 


\begin{tabular}{|c|c|c|}
\hline Date & Event & Description \\
\hline 8 May 2019 & $\begin{array}{l}\text { New citation required but conclusions } \\
\text { have not changed }\end{array}$ & $\begin{array}{l}\text { New review authors added. Background updated. Searches up- } \\
\text { dated but no new studies found. Conclusions remain the same. }\end{array}$ \\
\hline 8 May 2019 & New search has been performed & $\begin{array}{l}\text { Searches updated to February 2019. No additional eligible stud- } \\
\text { ies identified. }\end{array}$ \\
\hline 9 February 2016 & New search has been performed & $\begin{array}{l}\text { Searches updated to January 2016. No additional eligible studies } \\
\text { identified. }\end{array}$ \\
\hline 9 February 2016 & $\begin{array}{l}\text { New citation required but conclusions } \\
\text { have not changed }\end{array}$ & $\begin{array}{l}\text { There were no new randomised controlled trials. Conclusions are } \\
\text { the same. Change of contact person. }\end{array}$ \\
\hline 17 December 2013 & $\begin{array}{l}\text { New citation required but conclusions } \\
\text { have not changed }\end{array}$ & $\begin{array}{l}\text { New review authors added. Modifications in text and style in con- } \\
\text { formity with Methodological Expectations of Cochrane Interven- } \\
\text { tion Reviews (MECIR) standards. }\end{array}$ \\
\hline 6 September 2013 & New search has been performed & $\begin{array}{l}\text { Searches updated to September 2013. No additional eligible } \\
\text { studies identified. }\end{array}$ \\
\hline 16 February 2009 & New search has been performed & $\begin{array}{l}\text { New searches: February 2009. New studies sought but none } \\
\text { found. Text in 'Assessment of risk of bias in included studies' } \\
\text { modified. Risk of bias table added. }\end{array}$ \\
\hline 8 August 2008 & Amended & Converted to new review format. \\
\hline
\end{tabular}

\section{CONTRIBUTIONS OF AUTHORS}

Zbys Fedorowicz (ZF), Esther J van Zuuren (EvZ), and Anirudha Agnihotry (AA) were responsible for data collection for the review; screening search results; screening retrieved papers against inclusion criteria; appraising risk of bias of papers; extracting data from papers; obtaining and screening data on unpublished studies; entering data into Review Manager; analysis and interpretation of data; and writing the review. Wendy Thompson (WT) and Julie Sprakel (JS) were responsible for updating the background and co-ordinating the update.

ZF and AA were responsible for organising retrieval of papers.

ZF and AA were responsible for writing to authors of papers for additional information; and providing additional data about papers.

ZF was responsible for designing and co-ordinating the review; and performing previous work that was the foundation of current study.

ZF, AA and EvZ were responsible for data management for the review.

ZF conceived the idea for the review.

AA will be the guarantor for the review.

\section{DECLARATIONS OF INTEREST}

Anirudha Agnihotry: none known.

Wendy Thompson: as a Doctoral Research Fellow at the University of Leeds, UK, my research about urgent dental care and antibiotic prescribing is funded by the National Institute for Health Research (NIHR) (the research arm of the National Health Service). From time to time, I also provide educational lectures for Health Education England about urgent dental care and drug prescribing in general dental practice. In addition, I hold a small contract with the University of Central Lancashire to provide lectures to undergraduate dental students as part of their microbiology and pharmacology courses. I am a specialist advisor (unpaid) for the National Institute for Health and Care Excellence (NICE) about antibiotic prescribing in dentistry and also sit on a NICE guideline development group of shared decision-making. Zbys Fedorowicz: none known.

Esther J van Zuuren: none known.

Julie Sprakel: none known.

\section{SOURCES OF SUPPORT}

\section{Internal sources}

- No sources of support supplied 


\section{External sources}

- Cochrane Oral Health Global Alliance, Other.

The production of Cochrane Oral Health reviews has been supported financially by our Global Alliance since 2011 (oralhealth.cochrane.org/partnerships-alliances). Contributors over the past year have been the American Association of Public Health Dentistry, USA; AS-Akademie, Germany; the British Association for the Study of Community Dentistry, UK; the British Society of Paediatric Dentistry, UK; the Canadian Dental Hygienists Association, Canada; the Centre for Dental Education and Research at All India Institute of Medical Sciences, India; the National Center for Dental Hygiene Research \& Practice, USA; New York University College of Dentistry, USA; NHS Education for Scotland, UK; and the Swiss Society for Endodontology, Switzerland.

- National Institute for Health Research (NIHR), UK.

This project was supported by the NIHR, via Cochrane Infrastructure funding to Cochrane Oral Health. The views and opinions expressed are those of the authors and not necessarily those of the Systematic Reviews Programme, NIHR, NHS or the Department of Health and Social Care.

\section{NOTES}

No new studies found for inclusion since review was first published in 2005. This Cochrane Review will not be updated until a substantial body of evidence on the topic becomes available. If trials are conducted and found eligible for inclusion in the future, the review would then be updated accordingly.

\section{INDEX TERMS}

\section{Medical Subject Headings (MeSH)}

Analgesics, Non-Narcotic [ ${ }^{\star}$ therapeutic use]; Anti-Bacterial Agents [ ${ }^{\star}$ therapeutic use]; Pain Measurement; Pulpitis [ ${ }^{\star} d r u g$ therapy]; Randomized Controlled Trials as Topic

\section{MeSH check words}

Female; Humans; Male 